\section{RESEARCH ARTICLE \\ 10.1002/2017SW001674 \\ Midlatitude postsunset plasma bubbles observed over Europe during intense storms in April 2000 and 2001}

Key Points:

- Midlatitude postsunset plasma

bubbles observations with GNSS TEC during severe storms in 2000 and 2001

- Results indicate that the plasma bubbles were migrating north from low latitudes at virtual speed of $400 \mathrm{~m} / \mathrm{s}$

- Evidence of postsunset plasma enhancement and EIA extension to European midlatitudes presented

Correspondence to:

Z. T. Katamzi-Joseph,

zkatamzi@sansa.org.za

\section{Citation:}

Katamzi-Joseph, Z. T., J. B. Habarulema, and M. Hernández-Pajares (2017), Midlatitude postsunset plasma bubbles observed over Europe during intense storms in April 2000 and 2001, Space Weather, 15, 1177-1190, doi:10.1002/ 2017 SW001674.

Received 1 JUN 2017 Accepted 8 AUG 2017 Accepted article online 14 AUG 2017 Published online 18 SEP 2017

(2017. American Geophysical Union. All Rights Reserved.

\author{
Zama Thobeka Katamzi-Joseph ${ }^{1,2}\left(\mathbb{D}\right.$, John Bosco Habarulema ${ }^{1,2}(\mathbb{D}$, \\ and Manuel Hernández-Pajares ${ }^{3}(\mathbb{D}$
}

${ }^{1}$ South African National Space Agency, Space Science, Hermanus, South Africa, ${ }^{2}$ Department of Physics and Electronics, Rhodes University, Grahamstown, South Africa, ${ }^{3}$ Department of Mathematics, UPC-IonSAT, Barcelona, Spain

Abstract Plasma bubbles are prevalent features of the equatorial/low-latitude ionosphere which are seldom observed at middle and high latitudes. Understanding the influence of geomagnetic storms on plasma bubbles' migration to higher latitudes is an important space weather topic, since a geomagnetic storm is an important phenomenon of space weather. This paper reports on the first observations of postsunset/evening midlatitude plasma bubbles in the European sector during the main phase of severe storms (Dst $\leq-200 \mathrm{nT}$ ) on 6 April 2000 and 11 April 2001. Plasma depletions observed in Global Navigation Satellite System total electron content measurements are confirmed with those observed from in situ Defense Meteorological Satellite Program ion density measurements. The results show that the plasma bubbles were migrating north at virtual speeds of $400 \mathrm{~m} / \mathrm{s}$ and on each of the storm days they extended as far north as $\sim 42^{\circ}$ (geographic latitude). It is estimated that the plasma bubbles may have grown to a maximum apex height of approximately $4000 \mathrm{~km}$. During the time of bubble occurrence, the evening midlatitude plasma was enhanced and the equatorial ionization anomaly extended to European midlatitudes. In addition, evidence of the upward plasma motion was found in ionosonde $h_{m} F_{2}$ and $h^{\prime} F$ measurements, while the interplanetary electric field $E_{y}$ was enhanced. This was found to suggest that the possible mechanism for the enhancement of midlatitude plasma and subsequent midlatitude plasma bubbles occurrence was the eastward penetration electric field associated with $B_{z}$ southward turning.

\section{Introduction}

Plasma bubble irregularities are generally equatorial/low-latitude nighttime ionospheric plasma density depletions that have adverse effects on transionospheric radio signals used by advanced technologies that modern society has come to depend on, for example, for navigation as well as satellite timing, positioning, and communication. These irregularities are generated by the generalized Raleigh-Taylor (R-T) instability through various seeding mechanisms, such as neutral wind, gravity waves, and electric and magnetic fields [Hudson and Kennel, 1975; Kelley et al., 1976; Ott, 1978; Li et al., 2009a; Abadi et al., 2015]. Until recently, the zonal electric field has been the most directly identified factor in the generation of plasma bubbles [e.g., Abdu et al., 1992, 1997; Sekar et al., 1997; Fejer et al., 1999; Abdu, 2012; Kil, 2015]; however, recent studies [e.g., Fukao et al., 2006; Li et al., 2009a, 2016] have shown that gravity waves could also play an important role. During daytime the electric field is eastward and often shows an enhancement after sunset before it turns westward; this phenomenon is known as the prereversal enhancement (PRE). The PRE causes an enhanced upward $\mathbf{E} \times \mathbf{B}$ drift that rapidly lifts the $F$ region to higher altitudes thus creating a steep electron density gradient of the rising $F$ region which becomes unstable to density perturbations leading to higher R-T instability growth resulting in plasma bubble formation [Woodman, 1970; Farley et al., 1986; Kil and Heelis, 1998; Abdu, 2012; Abadi et al., 2015].

A geomagnetic storm, an important space weather phenomenon, may enhance or inhibit the development of plasma bubble depending mainly on the perturbations in the zonal electric field at the equator caused by the variable nature of the high-latitude and low-latitude coupling [Fejer et al., 1999; Carter et al., 2014a, 2014b; Tulasi Ram et al., 2015; Carter et al., 2016]. When the interplanetary magnetic field (IMF) $B_{z}$ component turns southward, high-latitude electric field penetrate to equatorial latitudes as prompt penetrating electric field (PPEF), or disturbance dynamo electric field (DDEF) [Senior and Blanc, 1984; Spiro et al., 1988]. Global thermospheric neutral wind circulation induced by high-latitude joule heating produce westward (eastward) daytime 
(nighttime) DDEF that generates long lasting electric field disturbances at middle and low latitudes [Blanc and Richmond, 1980; Horvath and Lovell, 2013; Tulasi Ram et al., 2015]. During the southward turning of the IMF $B_{z}$, the solar wind moves across the southward IMF and generates the interplanetary electric field (IEF) which is transferred from the magnetosphere to the ionospheric polar regions when the shielding is ineffective (i.e., undershielding) resulting in PPEF. The PPEF, eastward (westward) during the daytime (nighttime), penetrate to low latitudes within a few minutes causing disturbances that last about 2-3 h [Kelley et al., 1979; Spiro et al., 1988; Abdu, 2012; Horvath and Lovell, 2013; Tulasi Ram et al., 2015]. If the undershielding PPEF with eastward polarity in the postsunset sector while $B_{z}$ is southward (resulting in upward plasma drift) is superposed in phase with the normal upward vertical drift due to the PRE, conditions for plasma bubble development are significantly enhanced [Abdu, 2012].

Although plasma bubbles are primarily a feature of the equatorial/low-latitude region, a few studies have reported on their occurrence at midlatitudes. The plasma bubbles and associated irregularities at these latitudes are thought to be either an extension of the equatorial plasma bubbles which have risen to high apex heights and extended to higher latitudes along the magnetic field lines or local irregularities triggered by the Perkins instability [Li et al., 2009a]. A study by Sahai et al. [2001] reported observations of small-scale intensity depletions over Asian midlatitudes (specifically Japan) that were drifting at velocities of $20 \mathrm{~m} / \mathrm{s}$ in the southwest direction during the recovery period of the 12 February 2000 storm. They suggested that these depletions were generated from the interaction between mesoscale traveling ionospheric disturbances and enhanced regions of the equatorial ionization anomaly (EIA) based on total electron content measurements and therefore associated the depletions to equatorial plasma depletions. Looking at the same storm over the same region, Ma and Maruyama [2006] showed that the midlatitude plasma bubble's vertical drift was decreasing with altitude and time and concluded that since it was drifted northeast, it was triggered by the PPEF in the equator. However, although Li et al. [2009a] reported on low and midlatitudes plasma bubbles in the Chinese and Japanese sectors during the 10 November 2004 storm, they found that the midlatitude plasma bubbles over the Chinese sector were not linked to equatorial electrodynamics but may be due to the coupling between the Perkins and sporadic $E$ (i.e., $E_{s}$ ) layer instabilities as these bubbles were observed simultaneously with spread $F$ and $E_{s}$ layer.

In this paper we investigate postsunset plasma bubbles that were observed from ionospheric total electron content (TEC) measurements over the European midlatitudes following storm commencements of two severe storms (i.e., Dst $\leq-200$ nT as defined by Loewe and Prölss [1997]) on 6 April 2000 and 11 April 2001. The results suggest that these depletions are related to equatorial plasma bubbles as they are observed simultaneously with or after equatorial plasma bubbles seen from the Defense Meteorological Satellite Program (DMSP) ion densities and during the EIA extension to midlatitude regions.

\section{Data}

Parameters of the solar wind, i.e., $z$ component of the IMF, i.e., IMF $B_{z}$, and IEF $E_{y}$ as well as auroral index $(A E)$ and the symmetric component of the ring current index $(S Y M-H)$ have been used to examine the temporal evolutions of the two storms studied. In this study, the 1 min IMF $B_{z}$ and IEF $E_{y}$ measurements from the Advanced Composition Explorer (ACE) satellite are shifted to a dynamic model bow shock nose location and were obtained from the NASA Goddard Space Flight Center's OMNIWEB interface (https://omniweb.gsfc.nasa.gov./ form/omni_min.html). The 1 min geomagnetic indices, i.e., $A E$ and SYM- $H$, were obtained from the World Data Center for Geomagnetism, Kyoto University (wdc.kugi.kyoto-u.ac.jp) and were used to determine the strength of the geomagnetic and auroral activities, respectively. Note that SYM- $H$ essentially gives the same information about the strength of the ring current as the well established Dst index [lyemori, 1990; lyemori and Rao, 1996; Wanliss and Showalter, 2006] but sampled at higher temporal resolution than Dst.

Global Navigational Satellite System (GNSS) TEC observations are used to understand the impact of the storms under investigations on the ionosphere, in particular the appearance of plasma bubbles at European midlatitudes. Vertical TEC from several European GNSS stations, see Table 1 for coordinates, were obtained at $30 \mathrm{~s}$ temporal resolution and elevation cutoff of $30^{\circ}$ using an algorithm developed at Boston College. This algorithm uses L1 and L2 GPS frequencies (i.e., 1575.42 and $1227.60 \mathrm{MHz}$, respectively) to derive slant TEC and applies differential satellites code biases published by the University of Bern and receiver biases estimated by minimizing TEC variability between 02:00 and 06:00 local time to get absolute values [Seemala and Valladares, 2011]. In this algorithm slant TEC are mapped to vertical TEC, henceforth TEC, by using a thin shell model at an 


\begin{tabular}{|c|c|c|c|c|c|}
\hline $\begin{array}{l}\text { Station } \\
\text { Code }\end{array}$ & $\begin{array}{l}\text { Geographic } \\
\text { Latitude }\end{array}$ & $\begin{array}{l}\text { Geographic } \\
\text { Longitude }\end{array}$ & $\begin{array}{l}\text { Geomagnetic } \\
\text { Latitude }\end{array}$ & $\begin{array}{l}\text { Geomagnetic } \\
\text { Longitude }\end{array}$ & $\begin{array}{l}\text { Local Time } \\
\text { (Hours) }\end{array}$ \\
\hline \multicolumn{6}{|c|}{ GPS } \\
\hline ANKR & 39.89 & 32.76 & 32.24 & 104.97 & $\mathrm{UT}+2.18$ \\
\hline BUCU & 44.46 & 26.13 & 39.26 & 99.37 & $\mathrm{UT}+1.74$ \\
\hline EBRE & 40.82 & 0.49 & 33.87 & 76.40 & $\mathrm{UT}+0.03$ \\
\hline GENO & 44.42 & 8.92 & 38.79 & 84.19 & UT+0.59 \\
\hline GRAS & 43.75 & 6.92 & 37.90 & 82.35 & $\mathrm{UT}+0.46$ \\
\hline MAD2 & 40.43 & 355.75 & 33.52 & 72.49 & UT-0.28 \\
\hline MARS & 43.28 & 5.35 & 37.27 & 80.93 & $\mathrm{UT}+0.36$ \\
\hline MATE & 40.65 & 16.70 & 34.01 & 90.18 & UT+1.11 \\
\hline $\mathrm{NICO}$ & 35.14 & 33.39 & 28.64 & 105.15 & $\mathrm{UT}+2.23$ \\
\hline NOTO & 36.88 & 14.99 & 28.75 & 88.08 & $\mathrm{UT}+1.00$ \\
\hline TUBI & 40.79 & 29.45 & 35.07 & 101.91 & UT+1.96 \\
\hline VILL & 40.44 & 356.05 & 33.52 & 72.73 & UT-0.26 \\
\hline \multicolumn{6}{|c|}{ lonosonde } \\
\hline EB040 & 40.80 & 0.50 & 33.84 & 76.40 & UT+0.03 \\
\hline
\end{tabular}

ionospheric altitude of $350 \mathrm{~km}$. TEC from several of GNSS stations used showed signatures of plasma depletions and therefore the rate of TEC index (ROTI), as defined by Pi et al. [1997], from these stations was derived to determine the temporal evolution of small-scale fluctuations. This parameter is often used to study ionospheric fluctuations [e.g., Basu et al., 1999; Nishioka et al., 2008; Li et al., 2009b; Oladipo and Schüler, 2013], since the 5 min ROTI detects ionospheric structures with a few kilometers spatial resolution, while plasma bubbles have scale sizes of the order of a hundred kilometers [Nishioka et al., 2008]. In situ ion density measurements obtained from DMSP F12, F13, and F15 satellites at altitudes of $\sim 850 \mathrm{~km}$ were analyzed and used to confirm TEC detected plasma bubbles. In addition, ground-based measurements from an ionosonde in Roquetes, Spain (EB040: $40.8^{\circ} \mathrm{N}, 0.5^{\circ} \mathrm{E}$; magnetic latitude $33.8^{\circ}$ ) were used for further investigation and insight on the origin of these irregularities.

\section{Results and Analysis}

\subsection{The 6 April 2000 Storm}

Figures $1 \mathrm{a}-1$ e show temporal evolution of the IMF $B_{z}$ component, solar wind speed, IEF $E_{y}$, and magnetic indices $A E$ and SYM- $H$ during the period 4-8 April 2000, while Figures $1 \mathrm{f}-1 \mathrm{j}$ show the same parameters but for the period 9-13 April 2001. From plots in Figures 1a-1e we observed that a storm commenced on 6 April 2000 when IMF $B_{z}$ turned strongly southward from around 16:00UT. It remained in this polarity for about $8.75 \mathrm{~h}$, until roughly 00:45 UT, and reached a minimum of approximately $-33 \mathrm{nT}$ at $\sim 23: 12 \mathrm{UT}$. After the southward turning of IMF $B_{z}$ the solar wind speed sharply increased from $365 \mathrm{~km} / \mathrm{s}$ (16:45 UT) to $585 \mathrm{~km} / \mathrm{s}$ (16:50 UT), reaching a maximum of $637 \mathrm{~km} / \mathrm{s}$ the next day (7 April) 09:12 UT. IEF $E_{y}$ also sharply increased from $1 \mathrm{mV} / \mathrm{m}$ (16:45 UT) to $12 \mathrm{mV} / \mathrm{m}(17: 16 \mathrm{UT})$, reaching a maximum of $19 \mathrm{mV} / \mathrm{m}$ at $\sim 23: 12$ UT. Subsequent to the southward turning of IMF $B_{z}$, a geomagnetic storm commenced with a sudden storm commencement at 16:40 UT, as indicated by a vertical red dashed line in Figures 1a-1e. During this storm, the $A E$ index increased sharply reaching a maximum of $2481 \mathrm{nT}$ at around 17:50 UT and SYM- $H$ decreased to a minimum of $-320 \mathrm{nT}$ at $\sim 00: 10$ UT on 7 April.

During this storm, GNSS TEC measurements from PRN 1 and PRN 16 over Spain (i.e., EBRE, MAD2, and VILL) exhibited plasma depletions between $~ 19: 35$ and 21:10 UT ( 19:35-21:10 LT) on 6 April 2000 (i.e., during the main phase of the storm), as seen in the top panel plots of Figure 2. Note that the color bar shows the geographic latitude range of the ionospheric pierce points (IPP), indicating that the latitudes at which these depletions are observed fall roughly between $40^{\circ} \mathrm{N}$ and $42^{\circ} \mathrm{N}$, corresponding to apex heights of roughly 3300 and $4000 \mathrm{~km}$. To get an idea of the width and depth (i.e., minimum dTEC) of the bubbles, the TEC data were detrended using a fourth-order polynomial to remove as much of the diurnal trend as possible. The TEC 

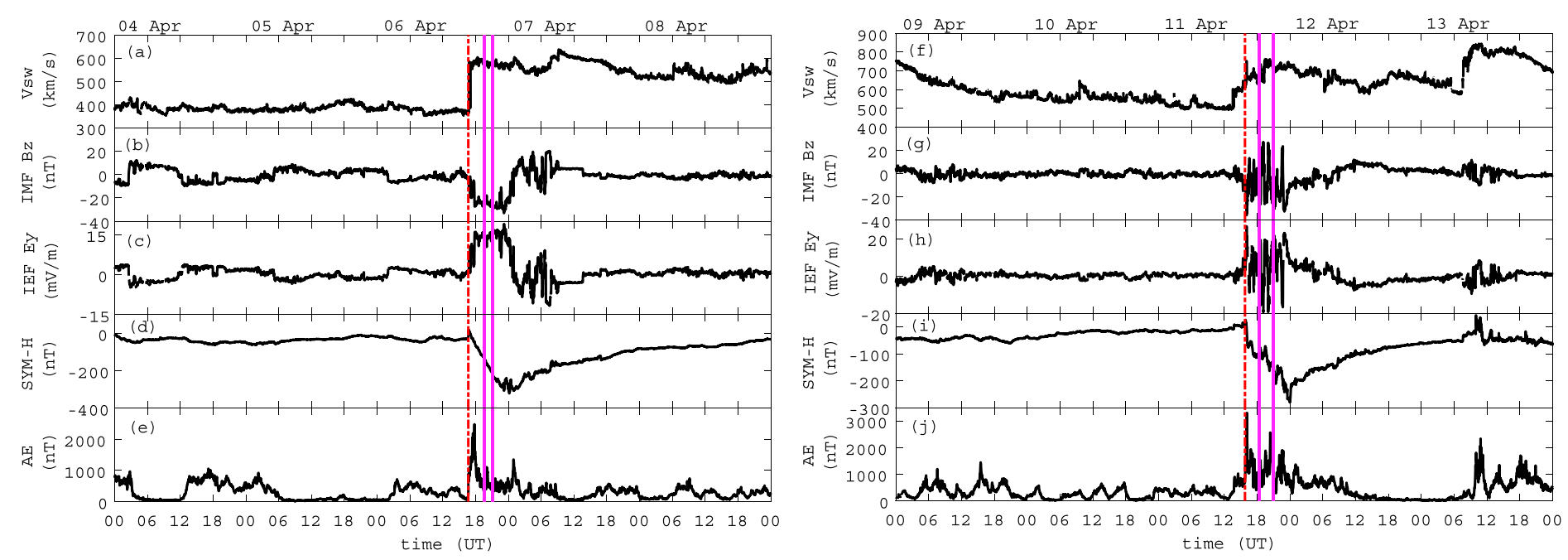

Figure 1. Interplanetary magnetic field $B_{z}$, solar wind $V_{s w}$, interplanetary electric field IEF $E_{y}$, and geomagnetic indices $A E$ and $S Y M-H$ during the period (a-e) 4-8 April 2000 and (f-j) 9-13 April 2001.
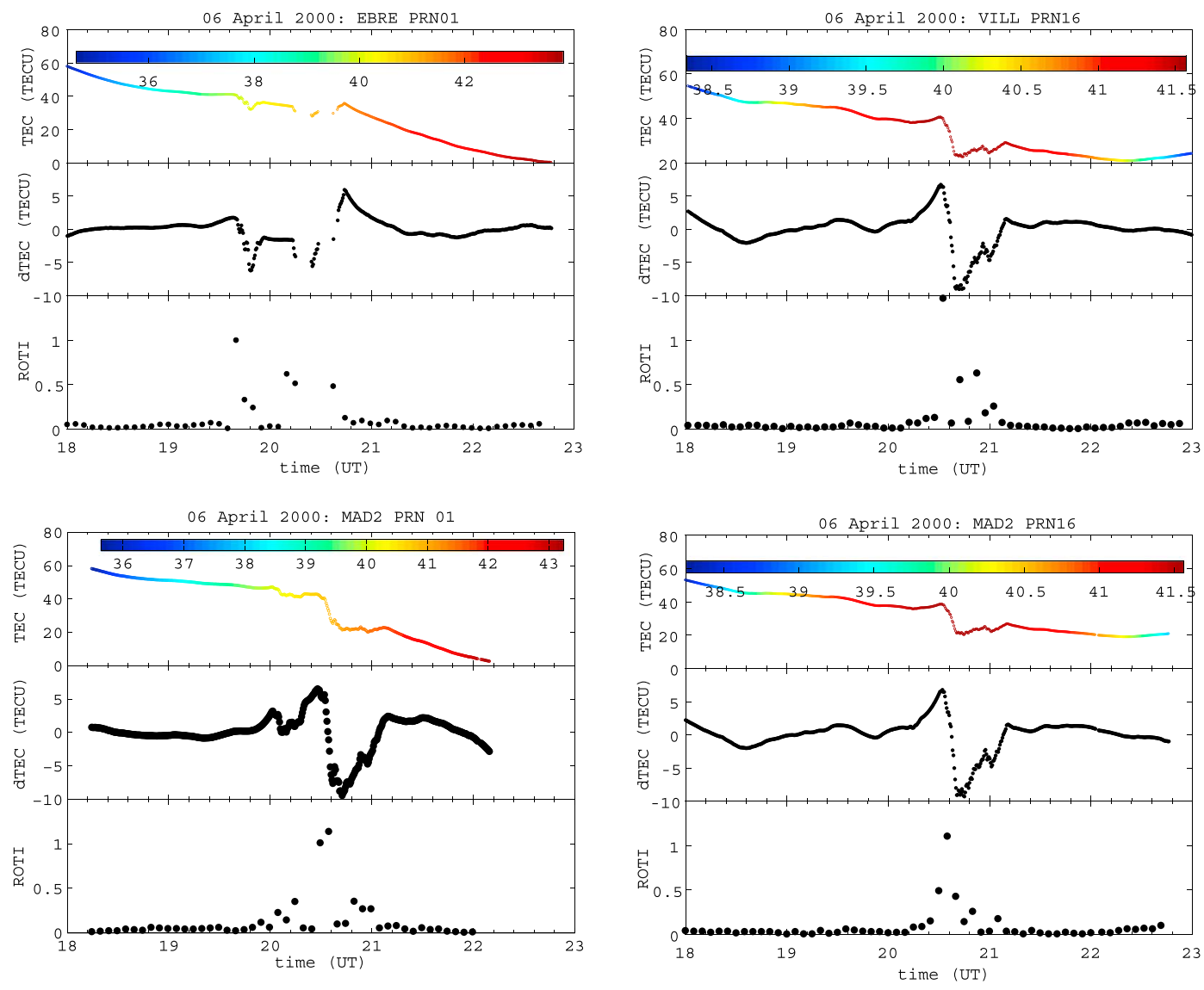

Figure 2. Temporal variation of TEC, TEC perturbations and ROTI during the main phase of 6 April 2000 storm. Color bar indicates IPP geographic latitude range. 

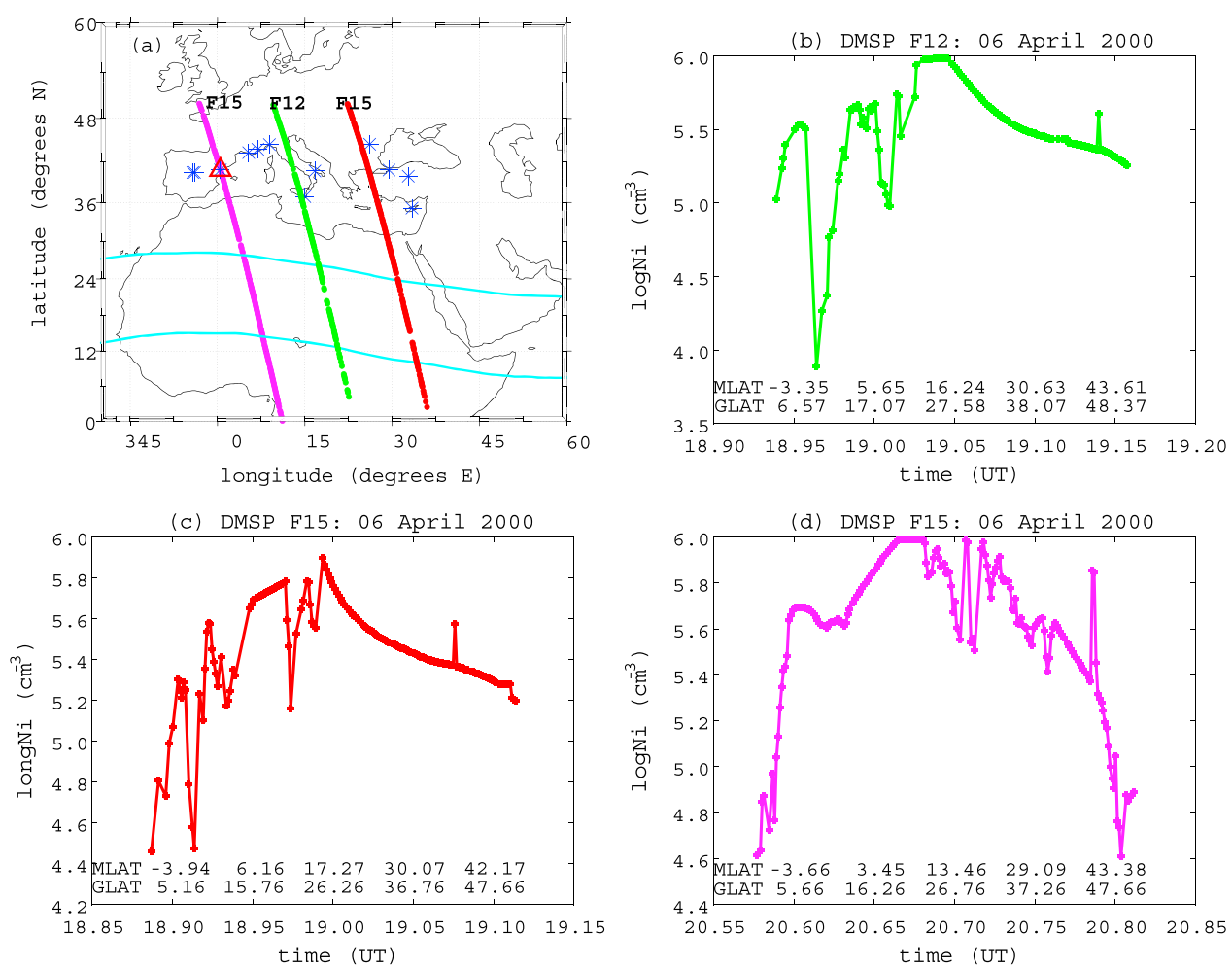

Figure 3. Ion densities measurements from DMSP satellites F12 and F15 on 6 April 2000. (a) Blue asterisks represent the location of the GNSS receivers; the red triangle represents the location of the ionosonde, while also showing the DMSP satellites tracks. $(b-d)$ The geomagnetic latitude (MLAT) and geographic latitude (GLAT) of the observations.

deviations/perturbations shown in the middle panel plots of Figure 2 reveal that the bubbles had widths of 16-38 minutes, and depth range of 6-9 TEC unit (TECU, $10^{16} \mathrm{el} \mathrm{m}^{-2}$ ). Corresponding to these bubbles, ROTI (shown in bottom panel plots of Figure 2) reached a maximum of about 0.6-1.1 TECU/min. These ROTI values correspond to weak amplitude scintillation $\left(S_{4}<0.4\right)$ caused by the presence of small-scale ionospheric irregularities such as plasma bubbles [Beach and Kintner, 1999; Basu et al., 1999]. The ROTI values associated with the bubbles observed in this study are also similar to those observed by Nishioka et al. [2008], Li et al. [2010], and Oladipo and Schüler [2013] for ionospheric irregularities at equatorial and low latitudes.

Figure 3a shows passes of DMSP satellites F12 and F15, while Figures $3 b-3 d$ show ion density measurements from these passes coincidental to the time of observations of TEC plasma depletions during the 6 April 2000 storm. Note that the cyan horizontal lines/curves in Figure 3a estimates the location of the magnetic equator and the northern crest of the EIA. These DMSP F12 and F15 results in Figures $3 \mathrm{~b}$ and $3 \mathrm{c}$ show plasma bubbles that were detected at equatorial and low latitudes, between roughly $3^{\circ} \mathrm{S}$ and $17^{\circ} \mathrm{N}$ geomagnetic latitudes $\left(5^{\circ}-27^{\circ} \mathrm{N}\right.$ geographic latitudes). Compared to the TEC plasma bubbles, the DMSP detected plasma bubbles appear earlier (i.e., around 18:54-19:02 UT) and at lower latitudes than those detected by the GNSS stations. However, these DMSP satellites passes are to the east (by about $15^{\circ}-30^{\circ}$ ) of the detecting GNSS stations, which may indicate that the bubbles originated from the equator and drifted northwest to appear at midlatitudes. The ion densities of DMSP F15 in Figure 3c show bubbles that may have extended from low to the middle latitudes $\left(10^{\circ}-30^{\circ} \mathrm{N}\right.$ geomagnetic latitudes, $20^{\circ}-39^{\circ} \mathrm{N}$ geographic latitudes) but still at lower latitudes than the GNSS receivers that detected similar TEC depletions. These bubbles appear at around the same time as the TEC depletions detected by MAD2 and VILL but a few minutes later than those detected by EBRE.

Figure 4 shows $R_{\mathrm{TEC}}$, representing the diurnal TEC deviation from the average of five quietest days of the month, for the period 4-8 April 2000 for the GNSS receivers presented in Table 1. $R_{\mathrm{TEC}}$ is calculated from $R_{\mathrm{TEC}}=\mathrm{TEC}-\overline{\mathrm{TEC}_{\text {quiet }}} / \overline{\mathrm{TEC}}$ quiet , where $\overline{\mathrm{TEC} \mathrm{C}_{\text {quiet }}}$ is the average of the five quietest day of the month. A TEC enhancement is observed throughout this period around 00-06 UT. However, on the day of the storm (6 April 2000) TEC is also enhanced around 19:00-23:00 UT (after storm's commencement and around the time of TEC and ion density depletions) at most stations, except BUCU, TUBI, and NICO which all fall east of $26^{\circ}$ longitude. 

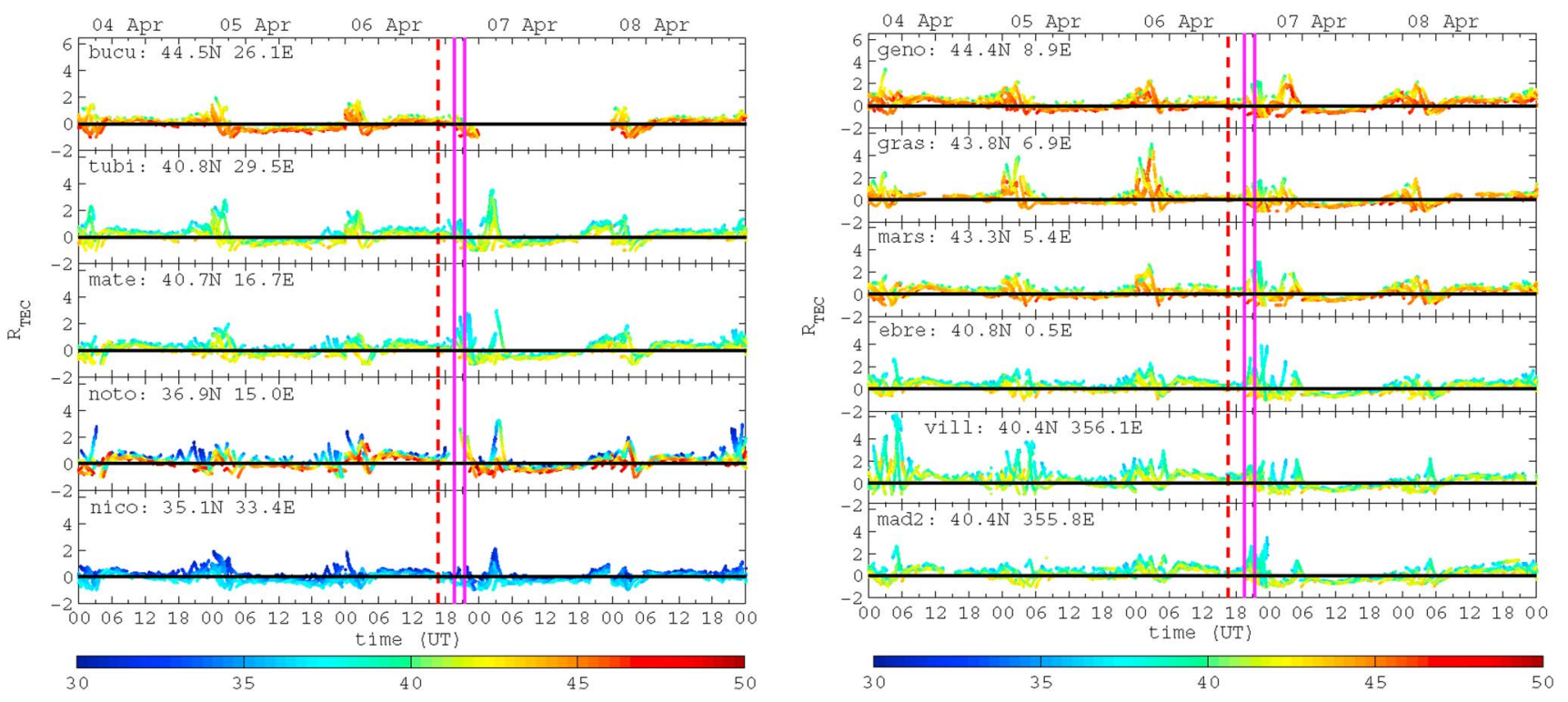

Figure 4. Ratio of diurnal TEC to average TEC of the five quietest days of the month, i.e. $R_{\text {TEC }}$, during the period $4-8$ April 2000 . The color bar represents IPP geographic latitude range.

The greatest enhancements are seen at EBRE, VILL, and MATE; plasma bubbles were detected from the former two stations, while none were detected from the later station. Also, the $R_{\text {TEC }}$ values are negative for much of the recovery period (7 April 2000), indicating that the TEC was much depleted compared to the quiet days of the month, which means that the storm had a negative storm effect on the European midlatitude ionosphere. A similar ionospheric depletion is also seen on the quiet day prior to the storm, i.e., 5 April, for most stations.

\subsection{The 11 April 2001 Storm}

It can be seen from Figures $1 \mathrm{f}-1 \mathrm{j}$ that the storm on 11 April 2001 started with IMF $B_{z}$ turning southward at around 14:37 UT, then rapidly alternating between northward and southward several times until 22:42 UT, and later staying mostly southward until $\sim 07: 47$ UT on 12 April. IMF $B_{z}$ reached its minimum value of approximately $-36 \mathrm{nT}$ around 16:04 UT. Although the IEF $E_{y}$ was enhanced (compared to the quiet days prior) reaching a maximum of $27 \mathrm{mV} / \mathrm{m}$ at $\sim 16: 04 \mathrm{UT}$, it also rapidly alternated between eastward (positive) and westward (negative). During this time the solar wind speed increased from $498 \mathrm{~km} / \mathrm{s}$ to a maximum of $762 \mathrm{~km} / \mathrm{s}$ at 19:27 UT. The IMF $B_{z}$ southward turning was followed by a sudden storm commencement at roughly 15:46 UT, and the storm peaked at $\sim 23: 57$ UT when SYM- $H$ reached a minimum of $-280 \mathrm{nT}$. As a result of the rapid fluctuations in IMF $B_{z}$, $A E$ also shows significant fluctuations as well as enhanced values, compared to quiet days before the storm, to reach a maximum of $\sim 3302 \mathrm{nT}$ at around 16:07 UT.

Figure 5 shows examples of plasma depletions detected through temporal evolution of TEC, detrended TEC, and ROTI measurements determined on 11 April 2001 at NICO, ANKR, and TUBI for PRNs 1, 13, 19, and 27. The top panel plots of this figure show TEC depletions between 18:17 and 21:00 UT where they appeared earlier at lower latitudes and later further north; for example, plasma depletions in PRN 1 TEC measurements appear at 18:17 UT (20:31 LT) at NICO, 18:38 UT (20:49 LT) at ANKR and 18:44 UT (20:41 LT) at TUBI, while depletions in PRN 13 TEC measurements appeared at 18:40 UT (20:54 LT) at NICO, 19:02 UT (21:13 LT) at ANKR and 19:20 UT (21:18 LT) at TUBI. These results indicate that the depletions were migrating north with estimated velocities of roughly $400 \mathrm{~m} / \mathrm{s}$ (PRN 1), reaching latitudes of $\sim 42^{\circ}$, again corresponding to an apex height of $\sim 4000 \mathrm{~km}$. The width and depth ranges of these depletions as obtained from the detrended TEC measurements (see middle panel plots of Figure 5) are roughly 11-60 min and 0.4-25.6 TECU, respectively. The maximum ROTI values of these depletions as seen from the bottom panel plots of Figure 5 vary between 0.3 and $2.8 \mathrm{TECU} / \mathrm{min}$, again corresponding to weak amplitude scintillation. Similar plasma bubbles are seen from in situ DMSP F13 and F15 ion density measurements, presented in Figures $6 b$ and $6 c$, respectively, but at equatorial and low latitudes. Satellite F15, whose track passes close to the NICO, ANKR, and TUBI GNSS receivers (see magenta track in Figure 6a), observed the plasma bubbles around the same time as those detected by PRNs 13 and 19 

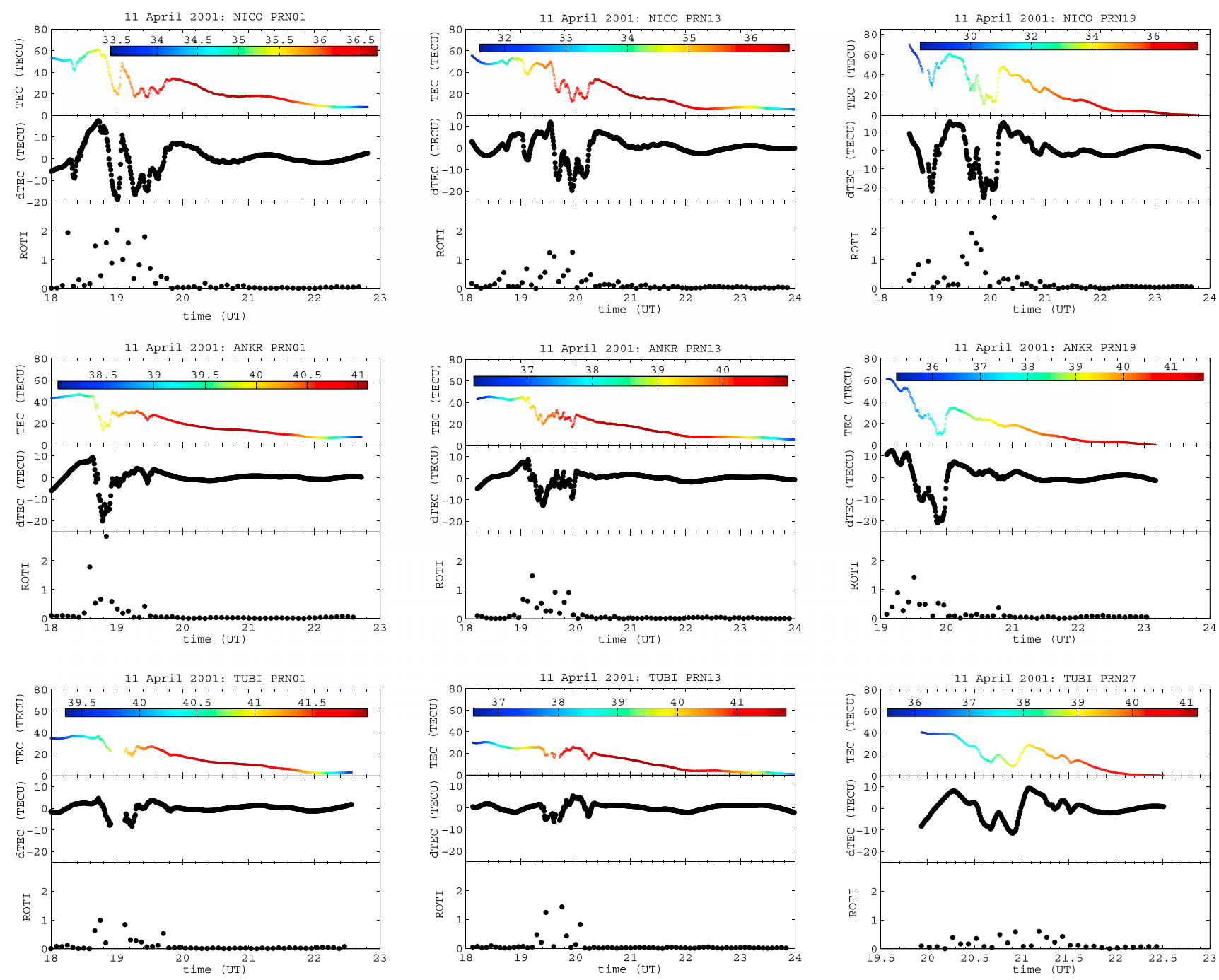

Figure 5. Temporal variation of TEC, TEC perturbations, and ROTI during the main phase of 11 April 2001 storm. Color bar indicates IPP geographic latitude range.
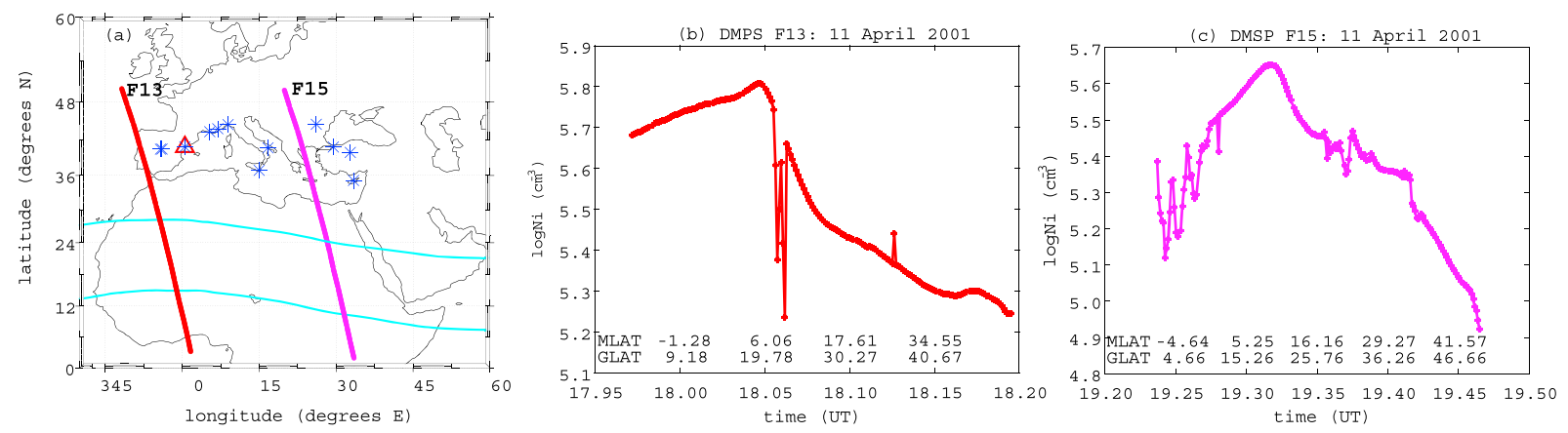

Figure 6. (a) lon densities measurements from DMSP's satellites F13 and F15 on 11 April 2001. Blue asterisks represent the location of the GPS receivers while the red triangle represents the location of the ionosonde, which were used in this study. (b and c) The geomagnetic latitude (MLAT) and geographic latitude (GLAT) of the observations 

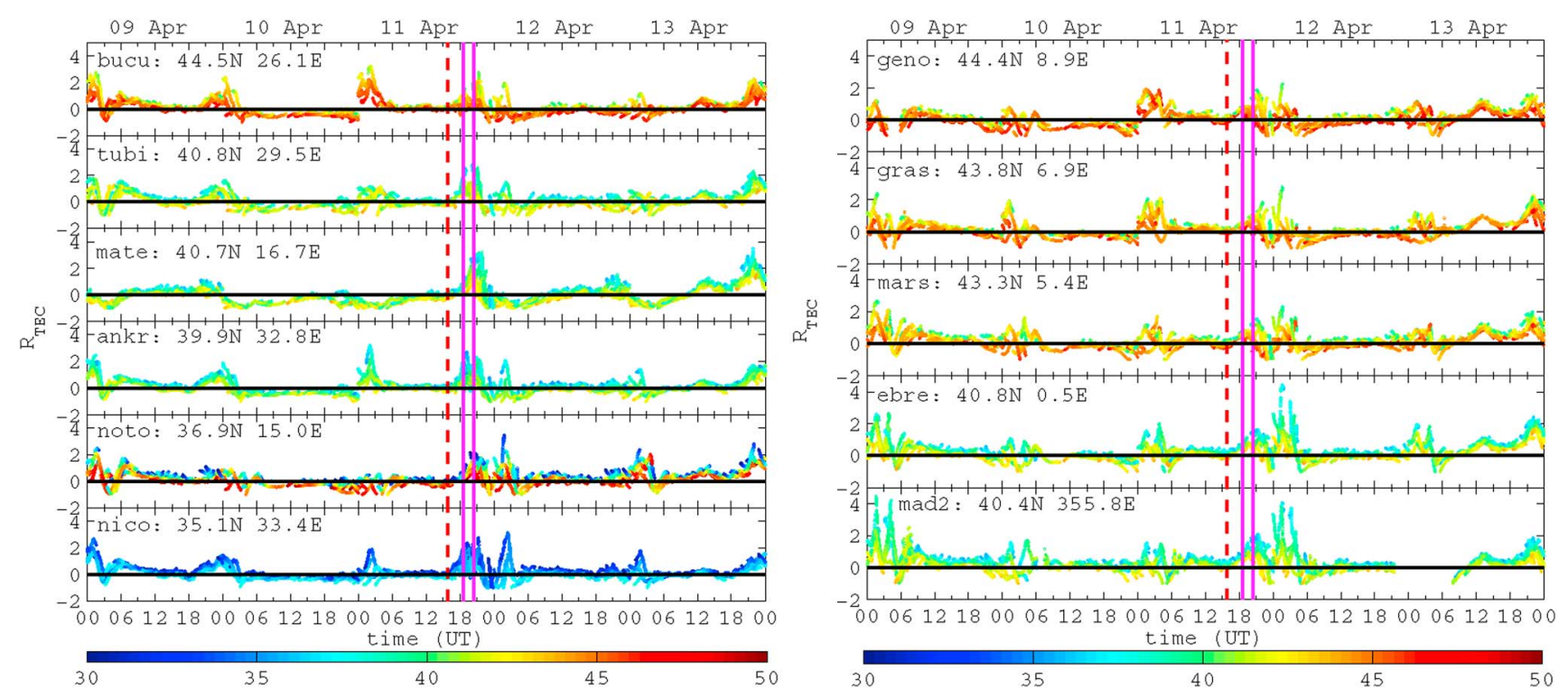

Figure 7. Ratio of diurnal TEC to average TEC of the five quietest days of the month, i.e. $R_{\text {TEC }}$ during the period $9-13$ April 2001. The color bar represents IPP geographic latitude range.

at midlatitudes, but earlier than those of PRN 27, implying that the TEC depletions may be associated with the equatorial bubbles. Also, the bubble observed from ion density measurement of satellite F13, whose track is further west than the GNSS receivers (see red track in Figure 6a), appeared much earlier than those detected by TEC measurements.

Figure 7 presents $R_{\mathrm{TEC}}$, i.e., diurnal TEC deviation from the average of five quietest days of the month, during the period 9-13 April 2001. These results show a significant TEC decrease the day prior to the storm (i.e., 10 April) compared to 9 April and the day of the storm (11 April) for most stations except MARS, EBRE, and MAD2. Following the storm commencement on 11 April and coincidental with the plasma depletion occurrences observed in GNSS and DMSP measurements, an evening TEC enhancement is observed at around 17:00-23:00 UT. This postsunset enhancement is seen roughly at the same time by all the GNSS stations used in this study and is of similar magnitude across the stations, unlike the postsunset enhancement of the previous storm which was observed by some of the stations used. Also, unlike the previously discussed storm (i.e., 6 April 2000 case), this storm does not appear to have caused a significant impact on the diurnal TEC trend of the day following the storm (i.e., 12 April 2001) over this European region, since the diurnal TEC trend on this day shows no significant changes compared to the quiet days prior to the storm. However, daytime and evening TEC enhancements were observed on 13 April 2001.

\section{Discussion}

Although several studies have reported on the ionospheric effects of the 6 April 2000 and 11 April 2001 storms [e.g., De Paula et al., 2004; Liu et al., 2004; Rothwell and Jasperse, 2006; Pimenta et al., 2007; de Abrue et al., 2010; Amabayo et al., 2012; Rastogi and Chandra, 2012; Horvath and Lovell, 2013], this study reports on new observations of postsunset midlatitude TEC depletions/bubbles during these storms. These depletions were observed to be moving north (specifically for 11 April 2001 case), reaching as far as $42^{\circ} \mathrm{N}$ geographic latitude, roughly corresponding to apex heights of roughly $4000 \mathrm{~km}$. Similarly, Ma and Maruyama [2006] detected midlatitude postsunset depletions, using a chain of GNSS receivers over Japan, which were migrating north during the main of phase of the 12 February 2000 storm. Their depletions reached latitudes of $\sim 36.5^{\circ} \mathrm{N}$ ( $\sim 31.5^{\circ}$ geomagnetic latitude) corresponding to an apex height of $2500 \mathrm{~km}$. In another study by Huang et al. [2007] midlatitude plasma depletions were observed during the 29 October 2003 storm which possibly reached magnetic latitudes of $46^{\circ} \mathrm{S}$ mapping to an apex height of $6830 \mathrm{~km}$. These studies suggested that their depletions were extensions of equatorial plasma bubbles and spread $F$ flux tubes into midlatitudes [Ma and Maruyama, 2006; Huang et al., 2007]. However, Sahai et al. [2001] and Li et al. [2009a] observed midlatitude 
bubbles that were migrating southward during storms on 12 February 2000 and 10 November 2004, respectively, and they suggested atmospheric gravity waves (AGWs)/traveling ionospheric disturbances (TIDs) as the seeding mechanism for these irregularities.

The plasma bubbles observed during IMF $B_{z}$ southward turning of the 6 April 2000 and 11 April 2001 storms in ion density DMSP measurements occur prior to and in the same vicinity as the TEC plasma depletions during a period of postsunset TEC enhancement. Huang [2011] explains that during the IMF $B_{z}$ southward turning equatorial/low-latitude penetration electric field is eastward in the evening, thus moving the $F$ region plasma upward and enhancing the growth of the Rayleigh-Taylor instability which results in conducive conditions for the generation of plasma bubbles. It is important to note that although the PPEF after IMF $B_{z}$ turns southward is eastward during the day and westward at night, some studies have found eastward penetration electric fields even at 22:00/23:00 LT [see, e.g., Sastri, 2002; Li et al., 2009a; Fejer et al., 2008; Chakrabarty et al., 2015]. Furthermore, according to $A b d u$ [2012], when an undershielding penetration electric field of eastward polarity associated with the storm main phase occurs in the evening, the vertical plasma drift is superposed in phase with normal vertical drift due to prereversal enhancement of electric field and as a result the conditions for plasma bubble development are significantly enhanced. Huang [2008] found that the eastward penetration electric field at dusk lasts for the duration of the southward IMF, causing large equatorial plasma uplifts. That study also showed that the penetration electric field in the dusk is approximately proportional to the IEF over the duration of the main phase of the storm. Furthermore, Huang et al. [2010] showed that the ionospheric electric field responsible for vertical plasma drift correlates well with variations of IEF. Therefore, the eastward IEF observed in Figure 1 indicates eastward penetration electric field and since the IMF $B_{z}$ in Figure 1 is southward for several hours, the penetration electric field will last just as long. It is therefore reasonable to deduce that the increase in postsunset TEC and subsequent plasma bubbles during the main phase of these storms may be driven by this eastward penetration electric field.

lonosonde measurements presented in Figure 8 show the electron density and height at the peak of the $F_{2}$ layer $\left(N_{m} F_{2}\right.$ and $h_{m} F_{2}$, respectively) as well as the virtual height $\left(h^{\prime} F\right)$ at Roquetes (closely located to the EBRE GNSS station) for the periods (a) 4-8 April 2000 and (b) 9-13 April 2001. At around 18:00 UT on the day of the 6 April 2000 storm, $h_{m} F_{2}$ drastically increased from $300 \mathrm{~km}$ to $490 \mathrm{~km}$ at 20:00 UT; an increase of $190 \mathrm{~km}$ in $2 \mathrm{~h}$. A similar increase is also seen from the $\mathrm{h}^{\prime} F$ measurements. The height measurements at this time are much higher than those at a similar time during the quiet days prior and post the storm and remain elevated throughout the time of observations of the plasma bubbles in Figures 2 and 3. Following the height increase, $N_{m} F_{2}$ increased from $0.94 \times 10^{12} \mathrm{el} / \mathrm{m}^{3}$ at 19:00 UT to $1.34 \times 10^{12} \mathrm{el} / \mathrm{m}^{3}$ at 20:00 UT. In addition, range and frequency spread $F$ activity was observed from Roquetes ionograms (not shown here) between 20:00 and 22:00 UT on this storm day, which further confirms the observations of plasma bubbles from midlatitude TEC measurements. Similarly, during the 11 April 2001 storm, $h_{m} F_{2}$ increased from $320 \mathrm{~km}$ at 16:00 UT to $373 \mathrm{~km}$ at 19:00 UT, while h'F increased from $233 \mathrm{~km}$ at 16:00 UT to $280 \mathrm{~km}$ at 18:00 as can been seen from Figure $8 \mathrm{~b}$. Although the height measurements are higher than those of quiet days, they decrease to prestorm conditions during the course of plasma depletion observations as indicated by the magenta vertical lines. Again, following the height increase $N_{m} F_{2}$ increased from $1.18 \times 10^{12} \mathrm{el} / \mathrm{m}^{3}$ at 19:00 UT to $1.56 \times 10^{12} \mathrm{el} / \mathrm{m}^{3}$ at 20:00 UT. However, no spread $F$ activity was observed from this ionosonde on this storm day. This is because for this storm day the midlatitude TEC plasma bubbles were observed along longitudes $29-34^{\circ} \mathrm{E}$, while the ionosonde is located at $0.5^{\circ} \mathrm{E}$. Similar to the TEC measurements, $N_{m} F_{2}$ is significantly reduced on the day after the 6 April 2000 storm (i.e., 7 April), while there were no significant changes to the diurnal trend of $N_{m} F_{2}$ on the day after the 11 April 2001 storm (i.e., 12 April). However, $N_{m} F_{2}$ is enhanced on 13 April 2001, supporting the TEC observation on the same day.

Enhancements of postsunset TEC measurements are within about an hour of the $h_{m} F_{2}$ uplift for the 6 April 2000 storm, while for the 11 April 2001 storm they occur immediately after uplift in the $h_{m} F_{2}$ measurements. The height increases occur within 1.5-2.5 h after the SSC of these storms. Also, an enhancement of eastward IEF is observed during the occurrences of the plasma bubbles, TEC enhancements, and height increases. PPEF produces rapid electrodynamics effects that last a few hours $(2-3 \mathrm{~h})$ following the sudden southward IMF turning [Huang et al., 2005; Horvath and Lovell, 2013]. Also, Huang et al. [2010] found that ionospheric electric field corresponding to upward plasma motion correlate well with variations of IEF $E_{y}$ for up to $21 \mathrm{~h}$ during the main and recovery phases of the magnetic storms. Therefore, it is not hard to imagine that these results, showing upward $F$ region movements, give further support of the eastward PPEF. Sahai et al. [2001] also found large $F$ region height changes (around 00:30 LT) with midlatitude small-scale depletions observed in OI 

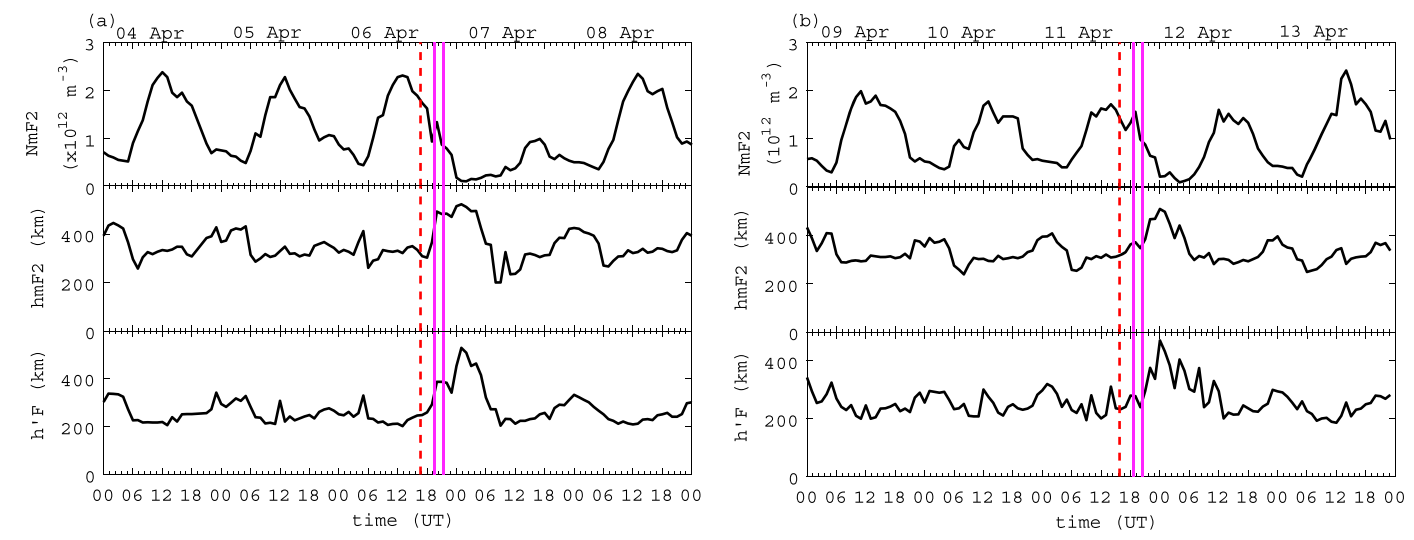

Figure 8. $F_{2}$ region peak density, virtual height, and peak height measurements obtained from the Ebre ionosonde during the period (a) 4-8 April 2000 and (b) 9-13 April 2001.

$630 \mathrm{~nm}$ airglow emission measurements from an all-sky imaging system, and they suggested that the depletions may be linked to electric field perturbations as well as large-scale atmospheric gravity waves. Similarly, Ma and Maruyama [2006] observed $h_{m} F_{2}$ uplifts (around 19:00-20:00 LT) accompanied by electron density enhancements over Japan following a 11 February 2000 storm commencement which they linked to prompt penetration of eastward electric field.

For long duration PPEF, as is the case for the storms in this study, conditions for plasma bubble development can occur over a wide longitudinal sector [Abdu, 2012]. For example, Tulasi Ram et al. [2008] observed plasma bubble activity over a wide longitudinal sector of $92^{\circ}$ during the 15-16 May 2005 storm, while a study by Li et al. [2010] reported longitudinal extension of over $\sim 200^{\circ}$ during a geomagnetic storm on 27 July 2004. However, recent studies by Carter et al. [2014a, 2014b, 2014c] showed that postsunset plasma bubbles were suppressed during small increases in the geomagnetic activity, but not necessarily high $K p$ ( $K p$ mostly less than 6). They concluded that prompt penetration of electric field were not the primary driver of daily variability of plasma bubble activity and proposed that perturbations in global-scale thermospheric winds were more influential in this regard. Another recent study by Anderson and Redmon [2017] observed that following periods of increased solar activity (using $F_{10.7}$ solar flux), PRE was inhibited from rising, which would have an effect of inhibiting plasma bubble activity. However, during the 17 March 2015 storm Carter et al. [2016] found that the postsunset plasma bubble activity in the Indian longitudinal sector was not suppressed during the storm's main phase, while they were suppressed at other longitudinal sectors. They concluded that the PPEF was effective in creating conditions conducive to plasma bubble generation on a narrow longitudinal range over which the postsunset local time coincides with the storm's main phase (i.e., before it reached its peak). In this study, DMSP detected plasma bubbles in a longitudinal range/extension of $\sim 38^{\circ}$, while GNSS TEC plasma bubbles had a longitudinal extension less than $\sim 10^{\circ}$. Since the main phases of both storms studied here coincided with the local postsunset time over the narrow European longitudinal sector where our measurements were taken, our results support the idea that the plasma bubbles were linked to the PPEF.

Li et al. [2009a] observed midlatitude plasma bubbles and simultaneous occurrence of spread $F$ irregularities associated with Perkins instability and sporadic $E\left(E_{s}\right)$ layer, which they found to indicate that the Perkins and $E_{s}$ layer instabilities coupling could enhance the growth rate for midlatitude ionospheric irregularities. Also, since a study by Pirog et al. [2007] observed TIDs at the same region for the same storm, Li et al. [2009a] concluded that the midlatitude plasma bubbles they observed were probably manifestations of gravity wave-Perkins instability resonance and coupling of $E_{s}$ layer and Perkins instabilities. To investigate whether the plasma depletions observed in this study were related to the $E_{s}$-Perkins instabilities coupling, we checked the ionosonde results for signatures of sporadic $E$ layer. Although the results are not shown here, hardly any $E_{s}$ activity was detected from the Roquetes ionosonde data during the main phase of the storm on 6 April 2000 (only at 18:00 UT), while there was significant $E_{s}$ activity during the recovery phase (7 April 18:00-22:00 UT) as well as the day after, i.e., 8 April 2000 17:00-20:00 UT. Similarly, there was no $E_{s}$ layer observed during the main phase of the 11 April 2001 storm while the $E_{s}$ layer occurred occasionally during the evenings of the quiet days 

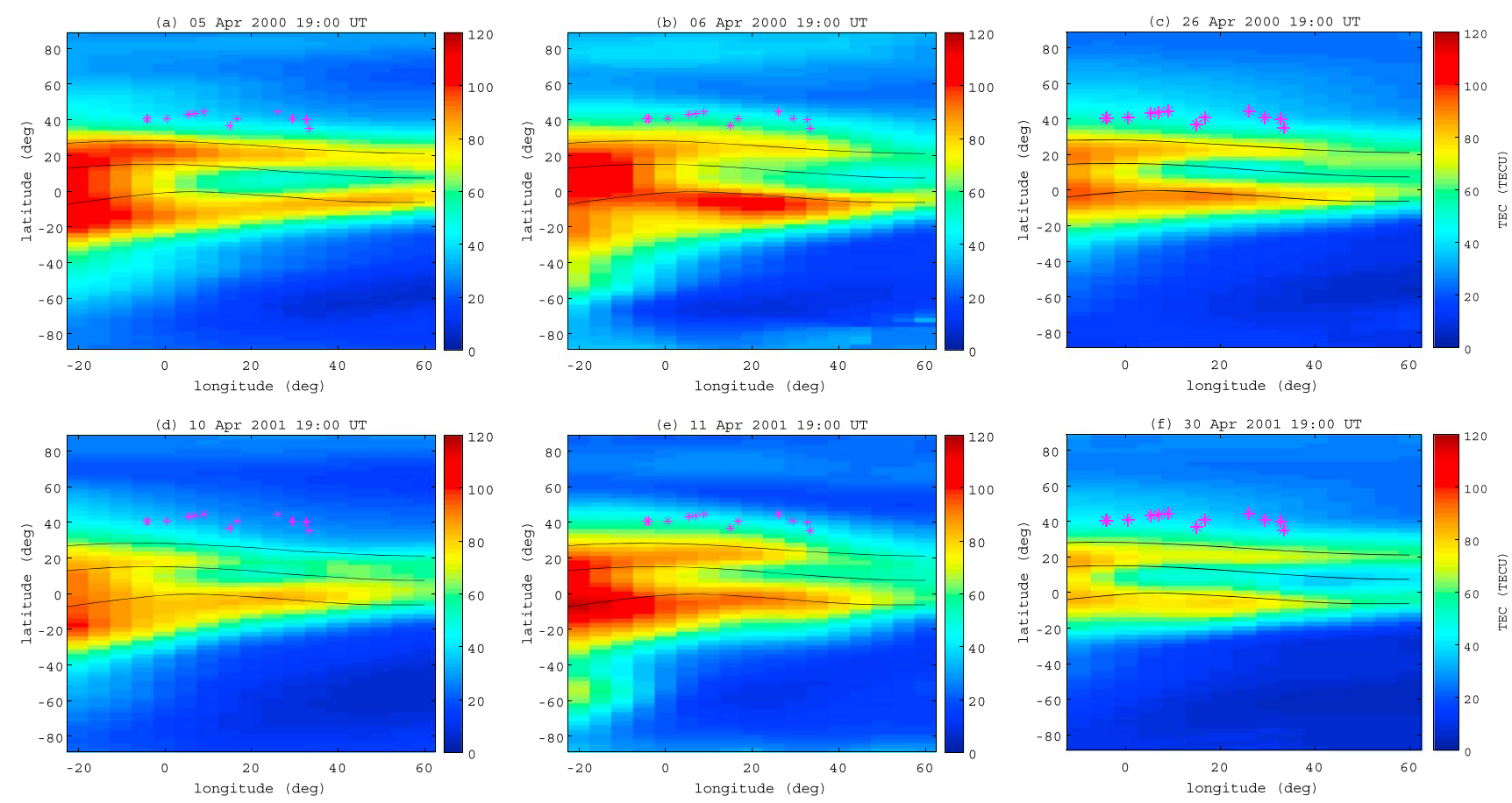

Figure 9. CODE's global TEC measurements over European-African longitudes at 19:00 UT for storm days ((b) 6 April 2000 and (e) 11 April 2001$)$, quiet days prior to storms ((a) 5 April 2000 and (d) 10 April 2001), and the quietest day of the month ((c) 26 April 2000 and (f) 30 April 2001). Color bar indicates TEC in TECU.

around this storm, for example, on 9 April 2001 between 18:00 and 00:00 UT and 12 April 2001 between 18:00 and 21:00 UT. Therefore, we can deduce that the plasma depletions observed in this study were not linked to $E_{s}$-Perkins instabilities coupling.

The midlatitude TEC depletions seen in Figures 2 and 5 are observed during the postsunset plasma enhancements seen in Figures 4 and 7, which further suggest that the depletions are linked to equatorial-type electrodynamics as a result of the expansion of the EIA as will be shown later using Figure 9. Note that in the later figures, the horizontal black curves approximates the magnetic equator as well as the southern and northern crests of the EIA. Figures $9 \mathrm{~b}$ and 9e show global GNSS TEC map over the Europe-Africa longitudes at 19:00 UT during the 6 April 2000 and 11 April 2001 storms, respectively, i.e., during the main phase of these storms. For comparisons, TEC on quiet days before these storms are shown in Figures 9a and 9d, as well as TEC on the quietest day of the month, i.e., 26 April 2000 and 30 April 2001, shown in Figures 9c and 9f, respectively. From these plots it is observed that the EIA expanded to midlatitudes during the main phase of both storms, compared to the quiet and quietest days, reaching the GNSS stations that observed TEC depletions. However, it is noted that the EIA expansion is more pronounced for the 11 April 2001 storm than the 6 April 2000 storm. The expansion of the EIA to midlatitudes during the main phase storms carries with it the conditions conducive to plasma upward drift and therefore suggests that the midlatitude ionosphere was susceptible to the eastward penetration electric field.

Ledvina et al. [2002] and Galav et al. [2014] presented similar midlatitude nighttime TEC depletions during geomagnetic storms on 25-26 September 2001 and 15 May 2005, respectively. They concluded the depletions were linked to the midlatitude ionospheric trough. This trough is a dominant evening and nighttime large-scale electron density depletion structure that is narrow in latitude and extended in longitude. The midlatitude trough is located a few degrees lower of the auroral oval and migrates to lower latitudes in the premidnight sector, and reverses its propagation around midnight to return to higher latitudes before dawn [He et al., 2011; Lee et al., 2011, and references therein]. In contrast to the midlatitude trough, the TEC depletions observed in this study were moving poleward during local evening time (at least for the 11 April 2001 storm), i.e., propagating in the opposite direction of the expected trough movement during this time. In addition, the extension of EIA region reached latitudes over which TEC bubbles were observed, as seen in Figures $9 \mathrm{~b}$ and $9 \mathrm{e}$. In fact, these figures show narrow regions (in latitude) of depleted TEC, suspected to be the midlatitude trough, at latitudes above which the TEC plasma bubbles were detected. Also, the TEC plasma 
bubbles observed in this study occur several hours after both storm commencements (i.e., $\sim 2.5-3 \mathrm{~h}$ after SSC), allowing for some time for them to be transported from the equatorial/low latitudes to midlatitudes. Therefore, it is reasonable to deduce that the TEC plasma bubbles observed in this study are not related to the midlatitude trough.

Other observations that were noticed during this study were the negative disturbances observed prior to both storms and negative ionospheric storm following the 6 April 2000 storm. Similar negative storm effects at similar and lower latitudinal regions were observed by Adebiyi et al. [2014]; Liu et al. [2004]; Afraimovich et al. [2002] for the same storm. These effects are probably produced by changes in neutral composition caused by Joule heating as a result of magnetospheric energy input at auroral regions [e.g., de Abrue et al., 2010; Prölss, 1995]. Negative quiet time disturbances are not well studied, and as a result, their source is not understood, but Mikhailov et al. [2007] and Mikhailovet al. [2009] have suggested that they may be linked to strong daytime poleward wind and low atomic oxygen concentration.

\section{Conclusion}

This paper has presented the first observations of midlatitude plasma depletions during two severe storms on 6 April 2000 and 11 April 2001 using GNSS TEC measurements, which were supported by equatorial plasma bubbles observed with DMSP ion density measurements. At the time of plasma bubble activity during both these storms, the evening sector midlatitude TEC and electron density (from nearby ionosonde) were enhanced following the IMF $B_{z}$ southward turning. The evening midlatitude plasma enhancement observations were supported by drastic upward lifting of the ionosphere observed in $h_{m} F_{2}$ and h'F measurements (within $\sim 2.5 \mathrm{~h}$ after IMF $B_{z}$ southward turning) which correlated with enhanced eastward IEF. Simultaneous to the observations of plasma bubbles/depletions and plasma enhancements was the expansion of the equatorial ionization anomaly to midlatitude regions. These observations are consistent with eastward penetration electric field as a driving mechanism for plasma upliftment and bubble generation in the equatorial regions which then extended to midlatitudes. Therefore, the results presented here confirm the link of midlatitude plasma bubbles to equatorial plasma bubbles. As plasma bubbles are normally thought of as equatorial/low latitude phenomena, it is important to highlight space weather conditions under which they can extend to higher latitudes and bring along associated adverse effects on transionospheric radio propagation, such as loss of lock due to scintillation associated with plasma bubbles.

Acknowledgments

The authors thank the ACE SWEPAM instrument team and the ACE Science Center for providing the ACE data (obtained from https://omniweb.gsfc.nasa.gov./ form/omni_min.html), the Center for Space Sciences at the University of Texas Dallas and the US Air Force for providing the DMSP plasma data (obtained from cindispace.utdallas.edu/DMSP/ dmsp_data_at_utdallas.html), the International GNSS Services for the provision of GNSS data (obtained from ftp://lox.ucsd.edu/pub/rinex/), Observatori de I'Ebre (Universitat Ramon Llull) for the provision data of the Spanish digisonde in Roquetes through GIRO site (can be accessed from ulcar.uml.edu/digisonde.html), and the Center for Orbit Determination in Europe (CODE)/Jet Propulsion Laboratory (JPL) for the IONEX products (obtained from ftp://cddis.gsfc.nasa.gov/pub/ gps/products/ionex/). $A E$ and SYM- $H$ data were downloaded from wdc.kugi.kyoto-u.ac.jp. The authors are grateful to the reviewers and editors for their constructive comments.

\section{References}

Abadi, P., Y. Otsuka, and T. Tsugawa (2015), Effects of pre-reversal enhancement of E $\times$ B drift on the latitudinal extension of plasma bubble in Southeast Asia, Earth Planets Space, 67, 74, doi:10.1186/s40623-015-0246-7.

Abdu, M. A. (2012), Equatorial spread F/plasma bubble irregularities under storm time disturbance electric fields, J. Atmos. Sol. Terr. Phys., 75-76, 44-56, doi:10.1016/j.jastp.2011.04.024.

Abdu, M. A., I. S. Batista, and J. H. A. Sobral (1992), A new aspect of magnetic declination control of equatorial spread $F$ and $F$ region dynamo, J. Geophys. Res., 97(A10), 14897-14904.

Abdu, M. A., J. H. Sastri, J. MacDougall, I. S. Batista, and J. H. A. Sobral (1997), Equatorial disturbance dynamo electric field longitudinal structure and spread F: A case study from GUARA/EITS campaigns, Geophys. Res. Lett., 24(13), 1707-1710.

Adebiyi, S. J., I. A. Adimula, and O. A. Oladipo (2014), Seasonal variations of GPS derived TEC at three different latitudes of the southern hemisphere during geomagnetic storms, Adv. Space Res., 53, 1246-1254, doi:10.1016/j.asr.2014.01.028.

Afraimovich, E. L., Y. . F. Ashkaliev, V. M. Aushev, A. B. Beletsky, V. V. Vodyannikov, L. A. Leonovich, O. S. Lesyuta, Yu. V. Lipko, A. V. Mikhalev, and A. F. Yakovets (2002), Simultaneous radio and optical observations of the mid-latitude atmospheric response to a major geomagnetic storm of 6-8 April 2000, J. Atmos. Sol. Terr. Phys., 64, 1943-1955.

Amabayo, E. B., L. McKinnell, and P. J. Cilliers (2012), lonospheric response over South Africa to the geomagnetic storm of $11-13$ April 2001 , J. Atmos. Sol. Terr. Phys., 84-85, 62-74, doi:10.1016/j.jastp.2012.06.002.

Anderson, D. N., and R. J. Redmon (2017), Forecasting scintillation activity and equatorial spread F, Space Weather, 15, 495-502, doi:10.1002/2016SW001554.

Basu, S., K. M. Groves, J. M. Quinn, and P. Doherty (1999), A comparison of TEC fluctuations and scintillations at Ascension Island, J. Atmos. Sol. Terr. Phys., 61, 1219-1226.

Beach, T. L., and P. M. Kintner (1999), Simultaneous Global Positioning System observations of equatorial scintillations and total electron content fluctuations, J. Geophys. Res., 104(A10), 22,553-22,565.

Blanc, M., and A. D. Richmond (1980), The ionospheric disturbance dynamo, J. Geophys. Res., 85(A4), 1669-1686.

Carter, B. A., E. Yizengaw, J. M. Retterer, M. Francis, M. Terkildsen, R. Marshall, R. Norman, and K. Zhang (2014a), An analysis of the quiet time day-to-day variability in the formation of postsunset equatorial plasma bubbles in the Southeast Asian region, J. Geophys. Res. Space Physics, 119, 3206-3223, doi:10.1002/2013JA019570.

Carter, B. A., et al. (2014b), Geomagnetic control of equatorial plasma bubble activity modeled by the TIEGCM with Kp, Geophys. Res. Lett., 41, 5331-5339, doi:10.1002/2014GL060953.

Carter, B. A., et al. (2014c), Using solar wind data to predict daily GPS scintillation occurrence in the African and Asian low-latitude regions, Geophys. Res. Lett., 41, 8176-8184, doi:10.1002/2014GL062203. 
Carter, B. A., E. Yizengaw, R. Pradipta, J. M. Retterer, K. Groves, C. Valladares, R. Caton, C. Bridgwood, R. Norman, and K. Zhang (2016), Global equatorial plasma bubble occurrence during the 2015 St. Patrick's Day storm, J. Geophys. Res. Space Physics, 121, 894-905, doi:10.1002/2015JA022194.

Chakrabarty, D., D. Rout, R. Sekar, R. Narayanan, G. D. Reeves, T. K. Pant, B. Veenadhari, and K. Shiokawa (2015), Three different types of electric field disturbances affecting equatorial ionosphere during a long-duration prompt penetration event, J. Geophys. Res. Space Physics, 120, 4993-5008, doi:10.1002/2014JA020759.

de Abrue, A. J., Y. Sahai, P. R. Fagundes, F. Becker-Guedes, R. de Jesus, F. L. Guarnieri, and V. G. Pillat (2010), Response of the ionospheric F-region in the Brazilian sector during the super geomagnetic storm in April 2000 observed by GPS, Adv. Space Res., 45, 1322-1329, doi:10.1016/j.asr.2010.02.003.

De Paula, E. R., K. N. Iyer, D. L. Hysell, F. S. Rodrigues, E. A. Kherani, A. C. Jardim, L. F. C. Rezende, S. G. Dutra, and N. B. Trivedi (2004), Multi-technique investigations of storm-time ionospheric irregularities over the São Luí equatorial station in Brazil, Ann. Geophys., 22, 3513-3522.

Farley, D. T., E. Bonelli, B. G. Fejer, and M. F. Larsen (1986), The prereversal enhancement of the zonal electric field in the equatorial ionosphere, J. Geophys. Res., 91(A12), 13,723-13,728.

Fejer, B. G., L. Scherliess, and E. R. de Paula (1999), Effects of the vertical plasma drift velocity on the generation and evolution of equatorial spread F, J. Geophys. Res., 104(A9), 19,856-19,869.

Fejer, B. G., J. W. Jensen, and S.-Y. Su (2008), Seasonal and longitudinal dependence of equatorial disturbance vertical plasma drifts, Geophys. Res. Lett., 35, L20106, doi:10.1029/2008GL035584.

Fukao, S., T. Yokoyama, T. Tayama, M. Yamamoto, T. Maruyama, and S. Saito (2006), Eastward traverse of equatorial plasma plumes observed with the Equatorial Atmosphere Radar in Indonesia, Ann. Geophys., 24, 1411-1418.

Galav, G., S. S. Rao, S. Sharma, G. Gordiyenko, and R. Pandey (2014), lonospheric response to the geomagnetic storm of 15 May 2005 over midlatitudes in the day and night sectors simultaneously, J. Geophys. Res. Space Physics, 119, 5020-5031, doi:10.1002/2013JA019679.

He, M., L. Liu, W. Wan, and B. Zhao (2011), A study on the nighttime midlatitude ionospheric trough, J. Geophys. Res., 116, A05315, doi:10.1029/2010JA016252.

Horvath, I., and B. C. Lovell (2013), Equatorial westward electrojet impacting equatorial ionization anomaly development during the 6 April 2000 superstorm, J. Geophys. Res. Space Physics, 118, 7398-7409, doi:10.1002/2013JA019311.

Huang, C.-S. (2008), Continuous penetration of the interplanetary electric filed to the equatorial ionosphere over eight hours during intense geomagnetic storms, J. Geophys. Res., 113, A11305, doi:10.1029/2008JA013588.

Huang, C.-S. (2011), Occurrences of equatorial plasma bubbles during intense magnetic storms, Int. J. Geophys., 2011, 401858, doi: $10.1155 / 2011 / 401858$.

Huang, C.-S., J. C. Foster, and M. C. Kelley (2005), Long-duration penetration of the interplanetary electric field to the low-latitude ionosphere during the main phase of magnetic storms, J. Geophys. Res., 110, A11309, doi:10.1029/2005JA011202.

Huang, C.-S., J. C. Foster, and Y. Sahai (2007), Significant depletions of the ionospheric plasma density at middle latitudes: A possible signature of equatorial spread $F$ bubbles near the plasmapause, J. Geophys. Res., 112, A05315, doi:10.1029/2007JA012307.

Huang, C.-S., F. J. Rich, and W. J. Burke (2010), Storm time electric fields in the equatorial ionosphere observed near the dusk meridian, J. Geophys. Res., 115, A08313, doi:10.1029/2009JA015150.

Hudson, M. K., and C. F. Kennel (1975), Linear theory of equatorial spread F, J. Geophys. Res., 80(34), 4581-4590.

lyemori, T. (1990), Storm-time magnetospheric currents inferred from mid-latitude geomagnetic field variations, J. Geomagn. Geoelect., 42 , $1249-1265$.

lyemori, T., and D. R. K. Rao (1996), Decay of the Dst field of geomagnetic disturbance after substorm onset and its implication to storm-substorm relation, Ann. Geophys., 14, 608-618.

Kelley, M. C., G. Haerendel, H. Kappler, A. Valenzuela, B. B. Balsley, D. A. Carter, W. L. Ecklund, C. W. Carlson, B. Häusler, and R. Torbert (1976), Evidence for a Rayleigh-Taylor type instability and upwelling of depleted density regions during equatorial spread $F$, Geophys. Res. Lett., $3(8), 448-450$

Kelley, M. C., B. G. Fejer, and C. A. Gonzales (1979), An explanation for anomalous equatorial ionospheric electric fields associated with a northward turning of the interplanetary magnetic field, Geophys. Res. Lett., 6(4), 301-304.

Kil, H. (2015), The morphology of equatorial plasma bubbles - A review, J. Astron. Space Sci., 32(1), 13-19, doi:10.5140/JASS.2015.32.1.13. Kil, H., and R. A. Heelis (1998), Global distribution of density irregularities in the equatorial ionosphere, J. Geophys. Res., 108(A1), 407-417.

Ledvina, B. M., J. J. Makela, and P. M. Kitner (2002), First observations of intense GPS L1 amplitude scintillations at midlatitude, Geophys. Res. Lett., 29(14), 1659, doi:10.1029/2002GL014770.

Lee, I. . T., W. Wang, J. Y. Liu, C. Y. Chen, and C. H. Lin (2011), The ionospheric midlatitude trough observed by FORMOSAT-3/COSMIC during solar minimum, J. Geophys. Res., 116, A06311, doi:10.1029/2010JA015544.

Li, G., B. Ning, B. Zhao, L. Liu, W. Wan, F. Ding, J. S. Xu, J. Y. Liu, and K. Yumoto (2009a), Characterizing the 10 November 2004 storm-time middle-latitude plasma bubble event in Southeast Asia using multi-instrument observations, J. Geophys. Res., 114, A07304, doi:10.1029/2009JA014057.

Li, G., B. Ning, L. Liu, W. Wan, and J. Y. Liu (2009b), Effect of magnetic activity on plasma bubbles over equatorial and low-latitude regions in East Asia, Ann. Geophys., 27, 303-312.

Li, G., et al. (2010), Longitudinal development of low-latitude ionospheric irregularities during the geomagnetic storms of July 2004 , J. Geophys. Res., 115, A04304, doi:10.1029/2009JA014830.

Li, G., Y. Otsuka, B. Ning, M. A. Adbu, M. Yamamoto, W. Wan, L. Liu, and P. Abadi (2016), Enhanced ionospheric plasma bubble generation in more active ITCZ, Geophys. Res. Lett., 43, 2389-2395, doi:10.1002/2016GL068145.

Liu, L., W. Wan, C. C. Lee, B. Ning, and J. Y. Liu (2004), The low latitude ionospheric effects of the April 2000 magnetic storm near the longitude $120^{\circ} \mathrm{E}$, Earth Planets Space, 56, 607-612.

Loewe, C. A, and G. W. Prölss (1997), Classification and mean behavior of magnetic storms, J. Geophys. Res., 102(A7), 14,209-14,213.

Ma, G., and T. Maruyama (2006), A super bubble detected by dense GPS network at east Asian longitudes, Geophys. Res. Lett., 33, L21103, doi:10.1029/2006GL027512.

Mikhailov, A. V., V. H. Depuev, and A. H. Depueva (2007), Synchronous NmF2 and NmE daytime variations as a key to the mechanism of quiet-time F2-layer disturbances, Ann. Geophys., 25, 483-493.

Mikhailov, A. V., V. H. Depueva, and V. H Depuev (2009), Quiet time F2-layer disturbances: seasonal variations of the occurrence in the daytime sector, Ann. Geophys., 27, 329-337.

Nishioka, M., A. Saito, and T. Tsugawa (2008), Occurrence characteristics of plasma bubble derived from global ground-based GPS receiver networks, J. Geophys. Res., 113, A05301, doi:10.1029/JA2007JA012605. 
Oladipo, O. A., and T. Schüler (2013), Equatorial ionospheric irregularities using GPS TEC derived index, J. Atmos. Sol. Terr. Phys., 92, 78-82, doi:10.1016/j.jastp.2012.09.019.

Ott, E. (1978), Theory of Rayleigh-Taylor bubbles in the equatorial ionosphere, J. Geophys. Res., 83(A5), 2066-2070.

Pi, X., A. J. Mannucci, U. J. Lindqwister, and C. M. Ho (1997), Monitoring of global ionospheric irregularities using the worldwide GPS network, Geophys. Res. Lett., 24(18), 2283-2286.

Pimenta, A. A., Y. Sahai, J. A. Bittencourt, and F. J. Rich (2007), lonospheric plasma blobs observed by OI $630 \mathrm{~nm}$ all-sky imaging in the Brazilian tropical sector during the major geomagnetic storm of April 6-7, 2000, Geophys. Res. Lett., 34, L02820, doi:10.1029/2006GL028529.

Pirog, O. M., N. M. Polekh, S. V. Voeykov, G. A. Zherebtsov, and P. V. Tatarinov (2007), lonospheric disturbances in the East-Asian region during geomagnetic storm in November 2004, Adv. Space Res., 39(8), 1335-1341, doi:10.1016/j.asr.2007.01.017.

Prölss, G. W. (1995), lonospheric F-region storms, in Handbooks of Atmospheric Electrodynamics, vol. 2, pp. 195-248, CRC Press, Boca Raton, Fla.

Rastogi, R. G., and H. Chandra (2012), Response of equatorial electrojet during the super geomagnetic storm of April 2000, Indian J. Radio Space Phys., 41, 524-535.

Rothwell, P. L., and J. R. Jasperse (2006), Modeling the connection of the global ionopsheric electric field to the solar wind, J. Geophys. Res., 111, A03211, doi:10.1029/2004JA010992.

Sahai, Y., K. Shiokawa, Y. Otsuka, C. Ihara, T. Ogawa, K. Igarashi, S. Miyazaki, and A. Saito (2001), Imaging observations of midlatitude ionospheric disturbances during the geomagnetic storm of February 12, 2000, J. Geophys. Res., 106(A11), 24,481-24,492.

Sastri, J. H. (2002), Penetration electric fields at the nightside dip equator associated with the main impulse of the storm sudden commencement of 8 July 1991, J. Geophys. Res., 107(A12), 1448, doi:10.1029/2002JA009453.

Seemala, G. K., and C. E. Valladares (2011), Statistics of total electron content depletions observed over the South American continent for the year 2008, Radio Sci., 46, RS5019, doi:10.1029/2011RS004722.

Sekar, R., R. Sridharan, and R. Raghavarao (1997), Equatorial plasma bubble evolution and its role in the generation of irregularities in the lower F region, J. Geophys. Res., 102(A9), 20,063-20,067.

Senior, C., and M. Blanc (1984), On the control of magnetospheric convection by the spatial distribution of ionospheric conductivities, J. Geophys. Res., 89(A1), 261-286.

Spiro, R. W., R. A. Wolf, and B. G. Fejer (1988), Penetration of high-latitude-electric-field effects on low latitudes during SUNDIAL 1984, Ann. Geophys., 6(1), 39-50.

Tulasi Ram, S., P. V. S. Rama Rao, D. S. V. VD. Prasad, K. Niranjan, S. Gopi Krishna, R. Sridharan, and S. Ravindran (2008), Local time dependent response of postsunset ESF during geomagnetic storms, J. Geophys. Res., 113, A07310, doi:10.1029/2007JA012922.

Tulasi Ram, S., S. Kumar, S.-Y. Su, B. Veenadhari, and S. Ravindran (2015), The influence of Corotating Interaction Region (CIR) driven geomagnetic storms on the development of equatorial plasma bubbles (EPBs) over wide range longitudes, Adv. Space Sci., 55, 535-544, doi:10.1016/j.asr.2014.10.013.

Wanliss, J. A., and K. M. Showalter (2006), High resolution global storm index: Dst versus SYM-H, J. Geophys. Res., 111, A02202, doi:10.1029/2005JA011034.

Woodman, R. F. (1970), Vertical drift velocities and east-west electric fields at the magnetic equator, J. Geophys. Res., 75(31), 6249-6259. 